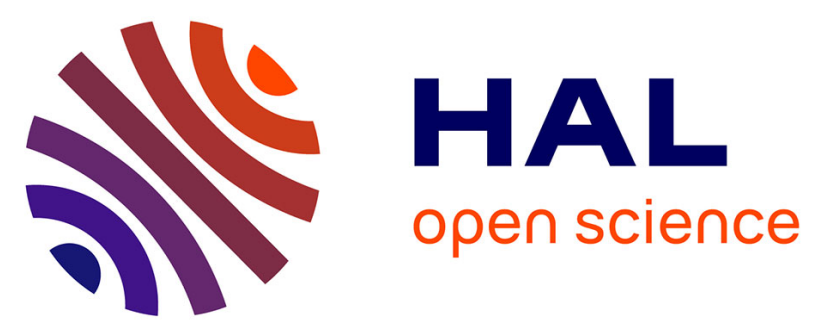

\title{
Reproductive allocation strategies: a long-term study on proximate factors and temporal adjustments in a viviparous lizard
}

Josefa Bleu, Jean-François Le Galliard, Patrick S. Fitze, Sandrine Meylan, Jean Clobert, Manuel Massot

\section{To cite this version:}

Josefa Bleu, Jean-François Le Galliard, Patrick S. Fitze, Sandrine Meylan, Jean Clobert, et al.. Reproductive allocation strategies: a long-term study on proximate factors and temporal adjustments in a viviparous lizard. Oecologia, 2013, 171 (1), pp.141-151. 10.1007/s00442-012-2401-1 . hal-03193611

\section{HAL Id: hal-03193611 \\ https://hal.science/hal-03193611}

Submitted on 8 Apr 2021

HAL is a multi-disciplinary open access archive for the deposit and dissemination of scientific research documents, whether they are published or not. The documents may come from teaching and research institutions in France or abroad, or from public or private research centers.
L'archive ouverte pluridisciplinaire HAL, est destinée au dépôt et à la diffusion de documents scientifiques de niveau recherche, publiés ou non, émanant des établissements d'enseignement et de recherche français ou étrangers, des laboratoires publics ou privés. 


\section{Reproductive allocation strategies: a long-term study on proximate}

\section{2 factors and temporal adjustments in a viviparous lizard}

3 Josefa Bleu*1,2, Jean-François Le Galliard ${ }^{1,3}$, Patrick S. Fitze ${ }^{4,5}$, Sandrine Meylan ${ }^{1,6}$, Jean

4 Clobert $^{7} \&$ Manuel Massot ${ }^{1}$

5

$6 \quad{ }^{1}$ CNRS ; UPMC ; ENS - UMR 7625, Laboratoire Ecologie et Evolution, 7 Quai St. Bernard, 775005 Paris, France.

$8 \quad{ }^{2}$ Université de Savoie ; CNRS - UMR 5553, Laboratoire d'Ecologie Alpine, 73370 Le Bourget 9 du Lac, France

$10{ }^{3}$ CNRS ; ENS - UMS 3194, CEREEP - Ecotron IleDeFrance, École Normale Supérieure, 78 11 rue du Château, 77140 St-Pierre-lès-Nemours, France.

$12{ }^{4}$ University of Lausanne, Department of Ecology and Evolution (DEE), Biophore, 1015

13 Lausanne, Switzerland.

$14{ }^{5}$ Instituto Pirenaico de Ecología (IPE-CSIC) and Fundación ARAID, Avenida Regimiento de 15 Galicia s/n, 22700 Jaca, Spain.

$16{ }^{6}$ IUFM de Paris - Université Sorbonne Paris IV, 10 rue molitor, 75016 Paris, France.

$17{ }^{7}$ CNRS, USR 2936, Station d'Ecologie Expérimentale du CNRS à Moulis, 09200 Saint Girons, 18 France.

19

$20 *$ Author for correspondence:

21 Université de Savoie - UFR CISM, UMR 5553 Laboratoire d'Ecologie Alpine - Josefa Bleu 2273376 Le Bourget du Lac Cedex

23 Tel: + 334797588 86; email: josefa.bleu@ gmail.com

25 The final publication is available at www.springerlink.com

26 Citation: J. Bleu, J.-F. Le Galliard, P. S. Fitze, S. Meylan, J. Clobert \& M. Massot (2013)

27 Reproductive allocation strategies: a long-term study on proximate factors and temporal

28 adjustments in a viviparous lizard. Oecologia. 171: 141-151. doi:10.1007/s00442-012-2401-1. 
Abstract

30 Optimisation of reproductive investment is crucial for Darwinian fitness, and detailed long-term

31 studies are especially suited to unravel reproductive allocation strategies. Allocation strategies

32 depend on the timing of resource acquisition, the timing of resource allocation, and trade-offs

33 between different life-history traits. A distinction can be made between capital breeders that fuel

34 reproduction with stored resources and income breeders that use recently acquired resources. In

35 capital breeders, but not in income breeders, energy allocation may be decoupled from energy

36 acquisition. Here, we tested the influence of extrinsic (weather conditions) and intrinsic (female

37 characteristics) factors during energy storage, vitellogenesis, and early gestation on reproductive

38 investment, including litter mass, litter size, offspring mass and the litter size and offspring mass

39 trade-off. We used data from a long-term study of the viviparous lizard, Lacerta (Zootoca)

40 vivipara. In terms of extrinsic factors, rainfall during vitellogenesis was positively correlated

41 with litter size and mass, but temperatures did not affect reproductive investment. With respect

42 to intrinsic factors, litter size and mass were positively correlated with current body size and

43 postpartum body condition of the previous year, but negatively with parturition date of the

44 previous year. Offspring mass was negatively correlated with litter size, and the strength of this

45 trade-off decreased with the degree of individual variation in resource acquisition, which

46 confirms theoretical predictions. The combined effects of past intrinsic factors and current

47 weather conditions suggest that common lizards combine both recently acquired and stored 48 resources to fuel reproduction. The effect of past energy store points out a trade-off between 49 current and future reproduction.

51 Keywords: capital breeder, energy allocation, phenotypic plasticity, viviparity, trade-off. 
54 Reproductive allocation decisions are of central interest in evolutionary ecology as they

55 determine lifetime reproductive success and some of the costs associated with reproduction (Roff

56 2002). It is possible to distinguish the allocation of resources to reproduction (i.e. how much to

57 invest in reproduction) and the allocation of reproductive resources between the size and number

58 of offspring. The energy invested into reproduction by a female depends on the total amount of

59 energy available, and reproductive investment as well as allocation rules are under maternal

60 and/or environmental (e.g. climatic) controls. In animals, there are capital breeding species that

61 fuel reproduction with stored resources and income breeding species that use recently acquired

62 resources (Stephens et al. 2009). Thus, in capital breeders pre-reproductive resource stores or

63 environmental conditions experienced during the energy storage period, such as food

64 availability, should correlate with future reproductive investment (Doughty and Shine 1997,

65 1998; Bonnet et al. 2001; Lourdais et al. 2002; Reading 2004) or future reproductive success

66 (Festa-Bianchet 1998). However, the capital and income breeding strategies describe only the

67 extremes of a continuum (e.g. Houston et al. 2007). Thus, females may adjust their energy

68 allocation strategy at multiple points in the reproductive cycle. In particular, adjustment of

69 offspring size or litter size may occur during gestation in viviparous (i.e. live-bearing) species

70 via embryo resorption or nutritional transfer. In viviparous lizards, for example, food and thermal

71 conditions experienced by the mother during gestation can affect offspring mass at birth (e.g.

72 Shine and Downes 1999; Swain and Jones 2000). A second aspect of reproductive investment

73 decisions is the existence of trade-offs between reproduction and other life-history traits,

74 including trade-offs between different reproductive events. In particular, current fecundity can

75 be traded-off with future fecundity. For example, a high investment in reproduction decreases

76 the probability to breed again and thus increases the inter-breeding interval (e.g. Bonnet et al. 
2001; Hadley et al. 2007), or a lower investment in reproduction increases survival later in life

78 (e.g. Clutton-Brock et al. 1983; Massot et al. 2011). In line with this trade-off hypothesis, 79 experiments in mammals (Koivula et al. 2003), lizards (e.g. Cox and Calsbeek 2010) and birds 80 (e.g. Richner and Tripet 1999; Hanssen et al. 2005) demonstrate that a higher reproductive effort results in a decrease in survival or fecundity the following year.

82 Finally, females can also adjust how the energy is allocated into each offspring (e.g. offspring 83 mass), i.e. how the trade-off between litter size and offspring mass is solved. Females may vary 84 in their resource stores and resource acquisition efficiency (Doughty and Shine 1997; Glazier 85 1999). The van Noordwijk and de Jong's model (1986) suggests that trade-offs will be weaker 86 if variation in resources acquisition is high relative to variation in resources allocation.

87 Furthermore, the pattern of energy allocation to offspring mass may follow distinct pathways. It 88 is often assumed that females decide in a sequential manner, first deciding how much to invest 89 into reproduction, and then, how much to invest in litter size versus offspring mass (e.g. Charnov 90 et al. 1995). However, investment and allocation decisions may also be simultaneous, genetically 91 linked, or correlated, as suggested by an old theoretical model (Winkler and Wallin 1987) and 92 by evidence from natural populations (Christians 2000; Uller et al. 2009).

93 Long-term studies are especially suited to disentangle the effects of past and present, and 94 extrinsic and intrinsic factors on both total reproductive investment and reproductive allocation 95 in litter size versus offspring mass. Squamate reptiles (i.e. lizards and snakes) are good model 96 species for such studies because they often lack parental care (Shine 2005), and thus reproductive 97 investment is completed during vitellogenesis and gestation in viviparous species. Moreover, 98 potential factors affecting the investment in reproduction are well identified. In many squamates, 99 body size influences reproductive output, such that larger females invest more in reproduction 100 than smaller females (e.g. Shine 2005). Some squamates are typical capital breeder but others 101 may also use mixed capital and income strategies (e.g. Bonnet et al. 2001; Houston et al. 2007). 
102 Weather conditions are also of particular importance for reproduction because they directly

103 affect habitat quality and food availability and also because foraging performances are linked to

104 the ability to maintain optimal body temperatures (Le Galliard et al. in press). Thus, we expect 105 that reproductive decisions should be largely dependent on pre-reproductive resource stores, 106 food availability and weather conditions in squamates. Moreover, because parturition dates 107 affect the duration of the energy storage period, early breeders may be able to capitalise more 108 resources than late breeders for the next reproductive event. In this study, we used 13 years of 109 field data on the viviparous common lizard, Lacerta (Zootoca) vivipara, to test the effects of 110 extrinsic factors (temperature and rainfall during the current and previous year) and intrinsic 111 factors (current body size, previous postpartum body condition (PBC), previous parturition date) 112 on reproductive output. From previous studies on the common lizard we know the following.

113 First, life-history traits are sensitive to variation in air temperature and rainfall (Chamaillé-

114 Jammes et al. 2006; Marquis et al. 2008; Le Galliard et al. 2010). Second, stored lipids decrease 115 during vitellogenesis (Avery 1974) and vitellogenesis occurs during a short period of 3 weeks 116 after winter emergence (Bauwens and Verheyen 1985), which are features of capital breeders.

117 Third, females can assimilate food during vitellogenesis (Avery 1975) and there are maternal 118 effects during gestation (e.g. Massot and Clobert 1995; Marquis et al. 2008), which are features 119 of income breeders.

120 Previous studies on L. vivipara addressed the effects of current weather (Marquis et al. 2008; Le 121 Galliard et al. 2010) and of social interactions (Le Galliard et al. 2008) on reproductive 122 investment, but none investigated the relative importance of past and present factors. We 123 therefore specifically tested the importance of the previous year's weather conditions and female 124 condition on reproductive investment. If common lizards are true capital breeders, we predict 125 that weather conditions during energy storage, $\mathrm{PBC}$ and/or parturition date of the previous year 126 should affect reproductive investment (litter mass, litter size and offspring mass). A correlation 
127 of reproductive investment decisions with weather conditions during vitellogenesis and/or

128 gestation would suggest income breeding. Finally, an intermediate situation would suggest a

129 mixed strategy. We expect the strength of the litter size and offspring mass trade-off to depend

130 on the variation in resource acquisition and resource allocation as predicted by the van

131 Noordwijk and de Jong's model (1986).

\section{MATERIAL AND MEthodS}

\section{Model species}

134 Lacerta (Zootoca) vivipara is a small (50-70 mm adult snout-vent length, SVL) ground-dwelling

135 lizard that is widely distributed across Eurasia. We studied viviparous populations located in the

136 Massif Central mountain range (south-eastern France) where the reproductive cycle is annual

137 (Fig. 1). In this area, adults start to become active around mid-April (males) or early May

138 (females). Emergence of the females from hibernation is highly synchronised, with mating

139 occurring 0-3 days after emergence and reproductive investment (vitellogenesis) occurring on

140 average during the first 3 weeks after emergence (Bauwens and Verheyen 1985) (first 3 weeks

141 of May for the Massif Central populations). During gestation, a primitive chorioallantoic

142 placenta allows respiratory, aqueous and mineral exchanges between mother and embryos

143 (Panigel 1956; Stewart et al. 2009). Parturition occurs after an average gestation period of 2

144 months, i.e. in late July to mid-August. Mean litter size is five (range 1-12), including both

145 nonviable offspring (fertilised or unfertilised eggs where only yolk is visible, undeveloped

146 embryos, and stillborns) and live offspring. Live offspring hatch immediately after parturition

147 and are thereafter autonomous. Adult females replenish their lipid stores during the summer

148 immediately after parturition and gradually enter into hibernation in September (Avery 1974;

149 Bauwens 1981).

150 Population survey and rearing conditions 
151 Longitudinal data on reproductive strategies were obtained from a long-term mark-recapture

152 survey conducted each year from 1990 to 2002 in a population at Mont-Lozère (1,420 m a.s.l.,

$15344^{\circ} 23^{\prime} 03^{\prime \prime} \mathrm{N}, 3^{\circ} 52^{\prime} 40^{\prime}$ 'E) that consists of two adjacent habitats with different structures (Clobert

154 et al. 1994). Adult females were captured on average 1 month before parturition (June), identified

155 or marked by toe-clipping, and kept in the laboratory until parturition (rearing conditions as in

156 Massot and Clobert 1995). After parturition, litter size was recorded, and females and their live

157 offspring were weighed. Females were then released together with their live offspring at the

158 original capture location 3-5 days after parturition. We recorded litter size for all litters (litters

159 containing exclusively viable offspring and litters containing nonviable offspring), and we

160 calculated litter mass and offspring mass only for litters containing exclusively viable offspring

161 (because we could not avoid the desiccation of the nonviable offspring and thus could not weight

162 them accurately). Litter mass was the sum of all offspring body masses, and offspring mass was

163 litter mass divided by litter size.

164 Weather

165 Temperature and rainfall data were recorded by Météo-France at a meteorological station 166 situated at a similar altitude, $50 \mathrm{~km}$ south of the study site (Mont Aigoual, $1,567 \mathrm{~m}$ a.s.1., $44^{\circ} 07^{\prime}$

167 N, $3^{\circ} 35^{\prime}$ E, see Chamaillé-Jammes et al. 2006; Marquis et al. 2008). We used daily maximum 168 temperature and daily cumulative amount of precipitation as descriptors of thermoregulation 169 opportunities and habitat humidity (Huey 1982). For each year, we calculated mean values for 170 different periods of the reproductive cycle, namely (1) during the previous summer activity 171 season (energy storage period), (2) during vitellogenesis, and (3) during the early gestation 172 period in natura (see Fig. 1 for more details). Correlations between these variables are reported 173 in Electronic Supplementary Material (ESM) 1. We tested the effects of temperature during 174 energy storage and temperature during early gestation both separately and together to address 
175 potential colinearity issues caused by a significant correlation between these variables. Effects

176 were all robust, and colinearity was therefore not a strong issue in our analyses.

\section{Offspring mass and litter size trade-off}

178 We also modelled the trade-off between offspring mass and litter size in more detail. Correlations 179 were run between offspring mass and residual litter size for each year (Pearson correlations). We

180 also ran correlations on log-transformed variables to make the results comparable with those 181 reported in recent publications (e.g. Christians 2000). Van Noordwijk and de Jong's model 182 (1986) predicts that more negative correlations should be found when variation in resource 183 acquisition is low compared to variation in resource allocation. Christians (2000) adapted the 184 van Noordwijk and de Jong's model (1986) to the litter size and offspring mass trade-off by 185 calculating the variation in resource acquisition as the variation in total reproductive investment, 186 i.e. variation in clutch or litter mass. Thus, as suggested by Christians (2000), we calculated the 187 allocation as $(\log ($ offspring mass $) /(\log ($ litter mass $))$ and the investment as $(\log (\operatorname{litter}$ mass $))$. 188 Then, to avoid the confounding effect of maternal size, we used the residuals of a linear 189 regression of these variables (investment or allocation) against maternal SVL (Christians 2000;

190 Brown 2003). We calculated the variances of these residuals to estimate the variation in female 191 investment and in female allocation. These variances were calculated for each year. We expect 192 a negative relationship between the ratio of allocation variance to investment variance and the 193 Pearson's correlation coefficient between offspring mass and litter size.

\section{Statistical analyses}

197 All statistical models were implemented in R 2.14.1 statistical software (http://cran.r198 project.org/). We analysed variation in the litter mass, litter size, and offspring mass at birth of 199 litters containing exclusively viable offspring $(n=157)$ and variation in litter size of all litters 
200 (i.e. litters containing exclusively viable offspring and litters containing nonviable offspring, $n$ $201=239$ ) with mixed-effects linear models, including year as a random effect (Pinheiro and Bates 202 2000) (lme procedure). The annual sample sizes are reported in ESM 2. Fifty females were 203 captured several times in two successive years, and the measurements performed on them cannot 204 be assumed independent. To be sure that there is no problem of pseudo-replication (only some 205 females appeared several times in the dataset) we also did the same statistical analyses with two 206 random effects: year and female identity (lmer procedure). Both analyses yielded very similar 207 results (see ESM 3 and 4 for the results with two random effects).

208 A first random-effect model was fitted to assess inter-annual variation. Then, a mixed-effect 209 model was fitted to test for intrinsic effects. In this model, we included, as explanatory variables,

$210 \mathrm{PBC}$ of the previous reproductive season $[\mathrm{PBC}(\mathrm{t}-1)]$, parturition date of the previous 211 reproductive season [parturition(t-1)], and female SVL during the current reproductive season $212[\mathrm{SVL}(\mathrm{t})]$. Body condition was calculated as residuals of a linear regression of body mass against 213 SVL. We also added a habitat effect (there are two habitats in our study site, see "population 214 survey and rearing conditions") because previous studies have reported spatial differences in life 215 history traits between these two habitats (Clobert et al. 1994). For offspring mass, we modelled 216 a potential trade-off with litter size. Since litter size and maternal SVL are correlated (Pearson's $217 r=0.66, P<0.0001$ ), we included relative litter size in the model (residuals of a linear regression 218 of litter size against maternal SVL). To test for potential differences between litters containing 219 exclusively viable offspring and litters containing at least one nonviable offspring, we included 220 a categorical effect ("success") when analysing all litters. The full model included additive and 221 first-order interaction terms. A first minimum adequate model was selected using both backward 222 elimination and forward selection of higher order interactions based on the Akaike Index 223 Criterion (AIC). Finally, additive effects of weather conditions were added to the first minimum 224 adequate model. A second minimum adequate model was then selected using the same procedure 
225 as mentioned above. We report only significant effects using F tests based on restricted maximum

226 likelihood conditional estimates of variance. Estimates \pm standard errors (SE) are shown for fixed

227 effects and the 95\% confidence intervals (CI) are given for random effects.

\section{RESULTS}

229 Reproductive data for 239 females, including 157 exclusively viable litters and 82 litters

230 containing nonviable offspring, were collected over a 13-year period. We found no effect of

231 temperature or habitat in any of the models tested (Table 1). The mass and size of litters

232 containing exclusively viable offspring were positively correlated with rainfall during

233 vitellogenesis (Table 1, Fig. 2), as well as with current female body size and with female PBC

234 the previous year (Fig. 3a). However, offspring mass was only explained by residual litter size

235 (litter size corrected by the maternal body size, Table 1). The size of all litters (litters containing

236 exclusively viable offspring and litters also containing nonviable offspring) increased with

237 rainfall during vitellogenesis and female body size, but was additionally influenced by the

238 interaction between the parturition date the previous year, PBC the previous year and litter

239 success of the current year (Table 1). In fact, consistent with the analysis reported above, the

240 interaction between parturition date and PBC the previous year was not significant for litters

241 containing exclusively viable offspring (partial test with "successful" litters: $\mathrm{F}_{1,141}=1.54, P=$

242 0.22). This interaction was significant for litters containing nonviable offspring (partial test with

243 "unsuccessful" litters: $\mathrm{F}_{1,66}=7.73, P=0.0071$, Fig. $3 \mathrm{~b}$ ). In these unsuccessful litters, $\mathrm{PBC}$ had

244 a positive effect on litter size for females giving birth late in the season but not for early breeders

245 (Fig. 3b).

246 Inter-annual variation was estimated using mixed-effects linear models with reproduction year 247 as random effect. Annual factors explained between 15.93 and $27.67 \%$ of the total inter-annual 248 standard deviation in reproductive traits (Table 2). Intrinsic factors (body size and condition) 
249 explained a large part of the inter-annual variation in litter size (for litters containing exclusively

250 viable offspring and all litters) and litter mass (Table 2), but inter-annual variation in offspring

251 mass remained unchanged when significant intrinsic factors (residual litter size) were included

252 in the model (Table 2). The effect of rainfall during vitellogenesis, which was significant for

253 litter mass and litter size, explained all remaining inter-annual variation in these two reproductive

254 traits (Table 2).

255 In litters containing exclusively viable offspring, the correlations between residual litter size and

256 offspring body mass were negative in all years (7 years not significant, Table 3 ) and there was

257 an annual variation in the strength of the correlation (Table 3). Our analysis confirmed the

258 existence of a strong, negative relationship between the variance ratio and the correlation

259 between litter size and offspring mass (Figure 4, Pearson's $r=-0.860$, range $=[-0.960 ;-0.566]$,

$260 \mathrm{P}=0.0003$ ). These results are in line with analyses based on log transformed values of offspring

261 mass and litter size (ESM 5).

\section{Discussion}

263 In this study we tested how weather conditions and female characteristics may affect

264 reproductive investment at different time scales, especially with regard to the relative importance

265 of past and present factors. Our major results are that reproductive investment is positively

266 correlated with current rainfall and female condition the year before, and is negatively correlated

267 with the parturition date of the previous reproduction. Our data also indicate that adjustments of 268 the reproductive investment occurred via the number of offspring and that offspring mass was 269 subsequently traded-off with litter size.

270 Reproduction and weather conditions

271 We investigated the effects of weather conditions on reproductive investment because they can

272 have direct or indirect effects. First, weather conditions can directly influence the metabolism 
273 and physiology of an animal. In particular, in ectotherms, it is known that temperatures influence

274 directly maternal activity (opportunity to feed), the efficiency of food assimilation (e.g. Adolph 275 and Porter 1993) and, during gestation, embryonic development (see below). Yet, in this study, 276 we found no effect of temperatures on litter size, litter mass and offspring mass at birth. Previous 277 laboratory experiments in viviparous squamates found effects of temperature or basking 278 opportunities during gestation on offspring mass (Shine and Harlow 1993; Doughty and Shine 279 1998; Swain and Jones 2000; Wapstra 2000; Hare and Cree 2010). Experiments in the laboratory 280 may not reflect the natural variations of thermal conditions and also may reduce the possibility 281 of a maternal response to compensate such variations. Some field studies have been conducted, 282 and different results have been found, with some authors finding no effect of temperature during 283 gestation on offspring size at birth (Vipera aspis Lourdais et al. 2004; Niveoscincus ocellatus, 284 Cadby et al. 2010) and other authors finding an effect of temperature during gestation on 285 offspring mass at birth but only at some altitudes (Niveoscincus ocellatus, Uller et al. 2011). 286 Thus, under natural conditions, females may be able to compensate for poor climatic conditions 287 - for example, by active thermoregulation - and may thus not be so strongly constrained by 288 thermal conditions (Webb et al. 2006). In particular, when there is strong selection to produce 289 larger offspring, females may be strongly selected to compensate for poor thermal conditions 290 (for example, despite an increased predation risk) (Uller et al. 2011).

291 Second, weather conditions can have indirect effects on females since they influence habitat 292 quality. Weather conditions influence environmental productivity and thus food availability: 293 more rainfall can be associated with a higher productivity and a higher reproductive investment 294 (e.g. Jordan and Snell 2002). In this case, the positive effect of rainfall during vitellogenesis on 295 reproductive investment may indicate income breeding for the common lizard. This result shows 296 that rainfall may be more important for successful breeding than thermal conditions. However, 297 the confirmation of underlying mechanisms and of income breeding will require direct tests of 
298 resource use either by measuring body composition and resource allocation with isotopic

299 analysis (e.g. Warner et al. 2008) or by manipulating the food intake during vitellogenesis (e.g.

300 Lourdais et al. 2003). We also observed that weather conditions experienced during gestation

301 had no effect on reproductive investment, confirming previous findings (Marquis et al. 2008;

302 Bleu et al. 2011). Finally, we observed that weather conditions experienced during energy

303 storage, here taken to correspond to the summer activity of the previous year, had no effect on

304 reproductive investment. Thus, this period may not be limiting for females. This result is in line

305 with an experimental manipulation in the common lizard: manipulation of food intake after

306 parturition during the summer revealed no major effect of food availability on reproductive

307 investment the following year (Mugabo et al. 2011).

308 Reproduction and intrinsic factors

309 Body size was positively correlated with current reproductive investment. Body size may limit

310 a female's reproductive output due to size-dependent availability of abdominal space (Qualls

311 and Shine 1995). Furthermore, larger lizards are usually more efficient foragers (González-

312 Suárez et al. 2011) and thus have more resources to allocate to reproduction than smaller lizards,

313 leading to a positive relationship between body size, fat body reserves and reproductive

314 investment (Avery 1974, 1975).

315 We also investigated the effects of $\mathrm{PBC}$ and parturition date of the previous year on current

316 reproduction. $\mathrm{PBC}$ indicates the resource stores of the female after reproduction, and parturition

317 date the previous year determines the length of the energy storage period. We found a positive

318 effect of PBC the previous year on current reproductive investment. This result may suggest

319 capital breeding as in other species (e.g. Doughty and Shine 1997; Festa-Bianchet 1998).

320 However, such a long-term effect of body condition is somewhat surprising since lizards can

321 store resources during the summer after reproduction and may thus compensate for a low PBC.

322 The lack of compensation suggests that feeding rate is positively correlated with body condition 
323 and that a low PBC indicates probably a low individual quality. In addition, we found a state-

324 dependent effect of the parturition date of the previous year on current reproductive investment

325 for females that produced litters containing nonviable offspring. In these cases, litter size was

326 constrained by PBC of the previous year when females gave birth late in the previous season,

327 but not when females gave birth early in the previous season. This illustrates that earlier breeding

328 and parturition may be advantageous for subsequent reproduction for some females.

329 The effect of previous PBC on current reproductive investment suggests a trade-off between

330 successive reproductive events, because a low PBC is associated with a stronger reproductive

331 effort in the common lizard (Le Galliard et al. 2010). The mechanisms of such trade-offs are

332 increasingly studied. First, there may be a simple energetic link between the two reproductive

333 events (Roff 2002): females that used more energy have fewer resources for the next season and

334 may not be able to compensate this difference. However, more complex scenarios are also

335 possible. Resources allocated to reproduction are not available for other functions, which may

336 thus be down-regulated as a consequence of a high reproductive investment, leading to a lower

337 investment in reproduction the following year. For example, a reduction of the investment in the

338 immune system may increase the risks of infection and thus decrease the condition of the female

339 and consequently its reproductive investment. Major functions that can be down-regulated are

340 the immune system (e.g. Gustafsson et al. 1994; Hanssen et al. 2005; French et al. 2007; Cox et

341 al. 2010), the oxidative defence (e.g. Alonso-Alvarez et al. 2004) and growth (e.g. Landwer

342 1994). Reduction in growth may be an important costs in species where female size is positively

343 correlated with female fecundity, as typically observed in squamates but also in other species

344 (e.g. in a crustacean, Berglund and Rosenqvist 1986). In this study we did not measured growth,

345 but we used female current size as a covariate in the statistical models. Thus, we have corrected

346 our analyses for potential differences in growth and quantified the effects of PBC and parturition 
347 date independently from their potential effects on growth. Future studies should attempt to

348 measure these different functions to understand their relative importance.

\section{Offspring mass and litter size trade-off}

350 More than two decades ago, van Noordwijk and de Jong (1986) suggested that trade-offs will be 351 more difficult to detect if variation in resources acquisition is high relative to variation in 352 resources allocation. We tested this hypothesis on the litter size and offspring mass trade-off. We 353 found a strong correlation between the variance ratio (i.e. the ratio of allocation variance to 354 investment variance) and the strength of the litter size and offspring mass trade-off, confirming 355 the prediction of the van Noordwijk and de Jong's model (1986). Previous studies in different 356 species and situations also confirmed this prediction. Christians (2000) explained inter-specific

357 variation in the strength of the trade-off between different bird species of the same order. This 358 prediction has also been confirmed at the intra-specific level between years or different 359 populations of the same species in scorpions (Brown 2003) and in lizards (Jordan and Snell 360 2002). In the common lizard, Uller and Olsson (2005) compared field and laboratory data for a 361 given year. They showed that the strength of the trade-offs was higher under laboratory 362 conditions, i.e. when variation in resources acquisition was presumably lower. Our study on a 363 multi-annual data set from a natural population also confirms the van Noordwijk and de Jong's 364 model (1986).

365 Despite annual variations in the strength of the litter size-offspring mass trade-off, we did not 366 detect variation in offspring mass that was independent of this trade-off. In particular, offspring

367 mass was not influenced by previous female reproduction nor by weather conditions before, 368 during or after vitellogenesis. Thus, our data indicate that adjustments of the reproductive 369 investment occurred via the number of offspring and that offspring mass was subsequently 370 traded-off with litter size. This result confirms that the litter size and offspring mass trade-off is 371 the major determinant of offspring mass (see also Bleu et al. 2012). Actually, an increased food 
372 intake caused by better weather conditions may not be invested in offspring mass (Massot and

373 Clobert 1995), these extra resources may instead be invested in female somatic growth, resulting

374 in higher PBC (Gregory 2006; Le Galliard et al. 2010).

\section{ACKNOWLEDGMENTS}

376 We are grateful to the students who helped collect data and to the Parc National des Cévennes

377 and the Office National des Forêts for providing good conditions during fieldwork. We thank

378 Météo-France for providing the weather data used in this study. Financial support was received

379 from the Agence Nationale de la Recherche (grant 07-JCJC-0120 to J.F.L.G and grant 07-

380 BLAN-0217 to M. M. and J. C.), the Spanish Ministry of Education and Science (CGL2005-

381 01187, CGL2008-01522, and Programa Ramón y Cajal to P. S. F.), the Swiss National Science

382 Foundation (PPOOP3_128375) and the Ministère de l'Éducation Supérieure et de la Recherche

383 (Ph.D grant to J. B.). The authors declare that they have no conflict of interest.

384 LITERATURE CITED

385 Adolph SC, Porter WP (1993) Temperature, activity, and lizard life histories. Am Nat 142:273-295. doi:10.1086/285538

387 Alonso-Alvarez C, Bertrand S, Devevey G, Prost J, Faivre B, Sorci G (2004) Increased susceptibility to oxidative stress as a proximate cost of reproduction. Ecol Lett 7:363368. doi:10.1111/j.1461-0248.2004.00594.x

390 Avery RA (1974) Storage lipids in the lizard Lacerta vivipara: a quantitative study. J Zool 173:419-425. doi:10.1111/j.1469-7998.1974.tb04124.x

392 Avery RA (1975) Clutch size and reproductive effort in the lizard Lacerta vivipara Jacquin. 
Bauwens D (1981) Survivorship during hibernation in the European common lizard, Lacerta vivipara. Copeia 1981:741-744. doi:10.2307/1444592

Bauwens D, Verheyen RF (1985) The timing of reproduction in the lizard Lacerta vivipara: differences between individual females. J Herpetol 19:353-364. doi:10.2307/1564263

Berglund A, Rosenqvist G (1986) Reproductive costs in the prawn Palaemon adspersus: effects on growth and predator vulnerability. Oikos 46:349-354. doi:10.2307/3565833

Bleu J, Le Galliard J-F, Meylan S, Massot M, Fitze PS (2011) Mating does not influence reproductive investment, in a viviparous lizard. J Exp Zool Part A 315A:458-464. doi:10.1002/jez.693

Bleu J, Massot M, Haussy C, Meylan S (2012) Experimental litter size reduction reveals costs 279:489-498. doi:10.1098/rspb.2011.0966

Bonnet X, Naulleau G, Shine R, Lourdais O (2001) Short-term versus long-term effects of food intake on reproductive output in a viviparous snake, Vipera aspis. Oikos 92:297-308. doi:10.1034/j.1600-0706.2001.920212.x

Brown CA (2003) Offspring size-number trade-offs in scorpions: an empirical test of the van Noordwijk and de Jong model. Evolution 57:2184-2190. doi:10.1111/j.00143820.2003.tb00397.x

Cadby CD, While GM, Hobday AJ, Uller T, Wapstra E (2010) Multi-scale approach to understanding climate effects on offspring size at birth and date of birth in a reptile. Integr Zool 5:164-175. doi:10.1111/j.1749-4877.2010.00201.x

Chamaillé-Jammes S, Massot M, Aragón P, Clobert J (2006) Global warming and positive fitness response in mountain populations of common lizards Lacerta vivipara. Global Change Biol 12:392-402. doi:10.1111/j.1365-2486.2005.01088.x 
418 Charnov EL, Downhower JF, Brown LP (1995) Optimal offspring sizes in small litters. Evol Ecol 9:57-63. doi:10.1007/BF01237697

420 Christians JK (2000) Trade-offs between egg size and number in waterfowl: an interspecific test of the van Noordwijk and de Jong model. Funct Ecol 14:497-501.

Clobert J, Massot M, Lecomte J, Sorci G, De Fraipont M, Barbault R (1994) Determinants of dispersal behavior: the common lizard as a case study. In: Vitt LJ, Pianka ER (eds) doi:10.1046/j.1365-2435.2000.00444.X Lizard ecology: historical and experimental perspectives. Princeton University Press,

Cox RM, Calsbeek R (2010) Severe costs of reproduction persist in Anolis lizards despite the Princeton, NJ, pp 183-206

Clutton-Brock TH, Guinness FE, Albon SD (1983) The costs of reproduction to red deer hinds.

Cox RM, Parker EU, Cheney DM, Liebl AL, Martin LB, Calsbeek R (2010) Experimental evolution of a single-egg clutch. Evolution 64:1321-1330. doi:10.1111/j.15585646.2009.00906.x evidence for physiological costs underlying the trade-off between reproduction and

Doughty P, Shine R (1998) Reproductive energy allocation and long-term energy stores in a survival. Funct Ecol 24:1262-1269. doi:10.1111/j.1365-2435.2010.01756.x

Doughty P, Shine R (1997) Detecting life history trade-offs: measuring energy stores in "capital" breeders reveals costs of reproduction. Oecologia 110:508-513. doi:10.1007/s004420050187 viviparous lizard (Eulamprus tympanum). Ecology 79:1073-1083. doi:10.1890/00129658(1998)079[1073:REAALT]2.0.CO;2

Festa-Bianchet M (1998) Condition-dependent reproductive success in bighorn ewes. Ecol Lett 1:91-94. doi:10.1046/j.1461-0248.1998.00023.x 
443 French SS, DeNardo DF, Moore MC (2007) Trade-offs between the reproductive and immune systems: facultative responses to resources or obligate responses to reproduction? Am Nat 170:79-89. doi:10.1086/518569

Glazier DS (1999) Trade-offs between reproductive and somatic (storage) investments in animals: a comparative test of the Van Noordwijk and De Jong model. Evol Ecol 13:539-555. doi:10.1023/A:1006793600600

González-Suárez M, Mugabo M, Decencière B, Perret S, Claessen D, Le Galliard J-F (2011) Disentangling the effects of predator body size and prey density on prey consumption in a lizard. Funct Ecol 25:158-165. doi:10.1111/j.1365-2435.2010.01776.x

452 Gregory PT (2006) Influence of income and capital on reproduction in a viviparous snake: direct and indirect effects. J Zool 270:414-419. doi:10.1111/j.1469-7998.2006.00149.x

454 Gustafsson L, Nordling D, Andersson MS, Sheldon BC, Qvarnström A (1994) Infectious diseases, reproductive effort and the cost of reproduction in birds. Philos Trans R Soc Lond B 346:323-331. doi:10.1098/rstb.1994.0149

457 Hadley GL, Rotella JJ, Garrott RA (2007) Evaluation of reproductive costs for Weddell seals in Erebus Bay, Antarctica. J Anim Ecol 76:448-458. doi:10.1111/j.13652656.2007.01219.x

Hanssen SA, Hasselquist D, Folstad I, Erikstad KE (2005) Cost of reproduction in a long-lived bird: incubation effort reduces immune function and future reproduction. Proc R Soc B 272:1039-1046. doi:10.1098/rspb.2005.3057 cover on offspring of a cool-temperate viviparous lizard. Biol J Linn Soc 101:844-851. doi:10.1111/j.1095-8312.2010.01536.x 
Houston AI, Stephens PA, Boyd IL, Harding KC, McNamara JM (2007) Capital or income breeding? A theoretical model of female reproductive strategies. Behav Ecol 18:241250. doi:10.1093/beheco/arl080

Huey RB (1982) Temperature, physiology, and the ecology of reptiles. In: Gans C, Pough FH (eds) Biology of the reptilia. Academic Press, New-York, pp 25-91

Jordan MA, Snell HL (2002) Life history trade-offs and phenotypic plasticity in the reproduction of Galapagos lava lizards (Microlophus delanonis). Oecologia 130:44-52. doi:10.1007/s004420100776

Koivula M, Koskela E, Mappes T, Oksanen TA (2003) Cost of reproduction in the wild: manipulation of reproductive effort in the bank vole. Ecology 84:398-405. doi:10.1890/0012-9658(2003)084[0398:CORITW]2.0.CO;2

Landwer AJ (1994) Manipulation of egg production reveals costs of reproduction in the tree lizard (Urosaurus ornatus). Oecologia 100:243-249. doi:10.1007/BF00316951

Le Galliard J-F, Cote J, Fitze PS (2008) Lifetime and intergenerational fitness consequences of harmful male interactions for female lizards. Ecology 89:56-64. doi:10.1890/06-2076.1

Le Galliard J-F, Marquis O, Massot M (2010) Cohort variation, climate effects and population dynamics in a short-lived lizard. J Anim Ecol 79:1296-1307. doi:10.1111/j.13652656.2010.01732.x

Le Galliard J-F, Massot M, Baron J-P, Clobert J (in press) Ecological effects of climate change on European reptiles. In: Brodie JF, Post E, Doak D (eds) Conserving wildlife populations in a changing climate. University of Chicago Press, Chicago

Lourdais O, Bonnet X, Shine R, Denardo D, Naulleau G, Guillon M (2002) Capital-breeding and reproductive effort in a variable environment: a longitudinal study of a viviparous snake. J Anim Ecol 71:470-479. doi:10.1046/j.1365-2656.2002.00612.x 
490 Lourdais O, Bonnet X, Shine R, Taylor EN (2003) When does a reproducing female viper (Vipera aspis) “decide” on her litter size? J Zool 259:123-129. doi:10.1017/s0952836902003059

493 Lourdais O, Shine R, Bonnet X, Guillon M, Naulleau G (2004) Climate affects embryonic 494 development in a viviparous snake, Vipera aspis. Oikos 104:551-560. doi:10.1111/j.0030-1299.2004.12961.X

Marquis O, Massot M, Le Galliard J-F (2008) Intergenerational effects of climate generate cohort variation in lizard reproductive performance. Ecology 89:2575-2583. doi:10.1890/07-1211.1

Massot M, Clobert J (1995) Influence of maternal food availability on offspring dispersal. Behav Ecol Sociobiol 37:413-418. doi:10.1007/BF00170589 doi:10.1111/j.1365-2435.2011.01837.x

504 Mugabo M, Marquis O, Perret S, Le Galliard J-F (2011) Direct and socially-mediated effects of food availability late in life on life-history variation in a short-lived lizard. Oecologia 166:949-960. doi:10.1007/s00442-011-1933-0

507 Panigel M (1956) Contribution à l'étude de l'ovoviviparité chez les reptiles: gestation et 508 parturition chez le lézard vivipare Zootoca vivipara. Ann Sci Nat Zool (XI) 18:569-668

509 Pinheiro JC, Bates DM (2000) Mixed-effects models in S and S-PLUS. Springer-Verlag, New510 York, NY

511 Qualls CP, Shine R (1995) Maternal body-volume as a constraint on reproductive output in lizards: evidence from the evolution of viviparity. Oecologia 103:73-78. doi:10.1007/BF00328427 
514 Reading CJ (2004) The influence of body condition and prey availability on female breeding success in the smooth snake (Coronella austriaca Laurenti). J Zool 264:61-67. doi:10.1017/S0952836904005515

517 Richner H, Tripet F (1999) Ectoparasitism and the trade-off between current and future reproduction. Oikos 86:535-538. doi:10.2307/3546657

Roff DA (2002) Life history evolution. Sinauer Associates, Sunderland, MA

Shine R (2005) Life-history evolution in reptiles. Annu Rev Ecol Evol Syst 36:23-46. doi:10.1146/annurev.ecolsys.36.102003.152631

522 Shine R, Downes SJ (1999) Can pregnant lizards adjust their offspring phenotypes to environmental conditions? Oecologia 119:1-8. doi:10.1007/s004420050754

524 Shine R, Harlow P (1993) Maternal thermoregulation influences offspring viability in a viviparous lizard. Oecologia 96:122-127. doi:10.1007/BF00318039

Stephens PA, Boyd IL, McNamara JM, Houston AI (2009) Capital breeding and income breeding: their meaning, measurement, and worth. Ecology 90:2057-2067. doi:10.1890/08-1369.1

Stewart JR, Ecay TW, Heulin B (2009) Calcium provision to oviparous and viviparous embryos of the reproductively bimodal lizard Lacerta (Zootoca) vivipara. J Exp Biol

532 Swain R, Jones SM (2000) Maternal effects associated with gestation conditions in a viviparous lizard, Niveoscincus metallicus. Herpetol Monogr 14:432-440. doi:10.2307/1467056

535 Uller T, Olsson M (2005) Trade-offs between offspring size and number in the lizard Lacerta vivipara: a comparison between field and laboratory conditions. J Zool 265:295-299. doi:10.1017/s0952836904006326 
Uller T, While GM, Cadby CD, Harts A, O’Connor K, Pen I, Wapstra E (2011) Altitudinal divergence in maternal thermoregulatory behaviour may be driven by differences in selection on offspring survival in a viviparous lizard. Evolution 65:2313-2324. doi:10.1111/j.1558-5646.2011.01303.x

542 Uller T, While GM, Wapstra E, Warner DA, Goodman BA, Schwarzkopf L, Langkilde T, Doughty P, Radder RS, Rohr DH, Bull CM, Shine R, Olsson M (2009) Evaluation of offspring size-number invariants in 12 species of lizard. J Evol Biol 22:143-151. doi:10.1111/j.1420-9101.2008.01629.x

van Noordwijk AJ, de Jong G (1986) Acquisition and allocation of resources: their influence on variation in life history tactics. Am Nat 128:137-142. doi:10.1086/284547

Wapstra E (2000) Maternal basking opportunity affects juvenile phenotype in a viviparous lizard. Funct Ecol 14:345-352. doi:10.1046/j.1365-2435.2000.00428.x

Warner DA, Bonnet X, Hobson KA, Shine R (2008) Lizards combine stored energy and recently acquired nutrients flexibly to fuel reproduction. J Anim Ecol 77:1242-1249. doi:10.1111/j.1365-2656.2008.01442.x

Webb JK, Shine R, Christian KA (2006) The adaptive significance of reptilian viviparity in the tropics: testing the maternal manipulation hypothesis. Evolution 60:115-122. doi:10.1554/05-460.1

Winkler DW, Wallin K (1987) Offspring size and number: a life history model linking effort per offspring and total effort. Am Nat 129:708-720. doi:10.1086/284667 


\section{TABLES}

560 Table 1. Effects of intrinsic and extrinsic factors on reproductive traits. Final models were selected

561 starting with full models. These included intrinsic factors [current body size: SVL(t), PBC of the previous

562 reproductive season: $\mathrm{PBC}(\mathrm{t}-1)$, parturition date of the previous reproductive season: Parturition(t-1), litter

563 success: Success], and extrinsic factors (habitat, rainfall and temperatures during energy storage,

564 vitellogenesis and gestation, see Fig. 1 for details). Residual litter size was calculated as the residuals of

565 a linear regression between litter size and maternal SVL. Random effects are presented in Table 2.

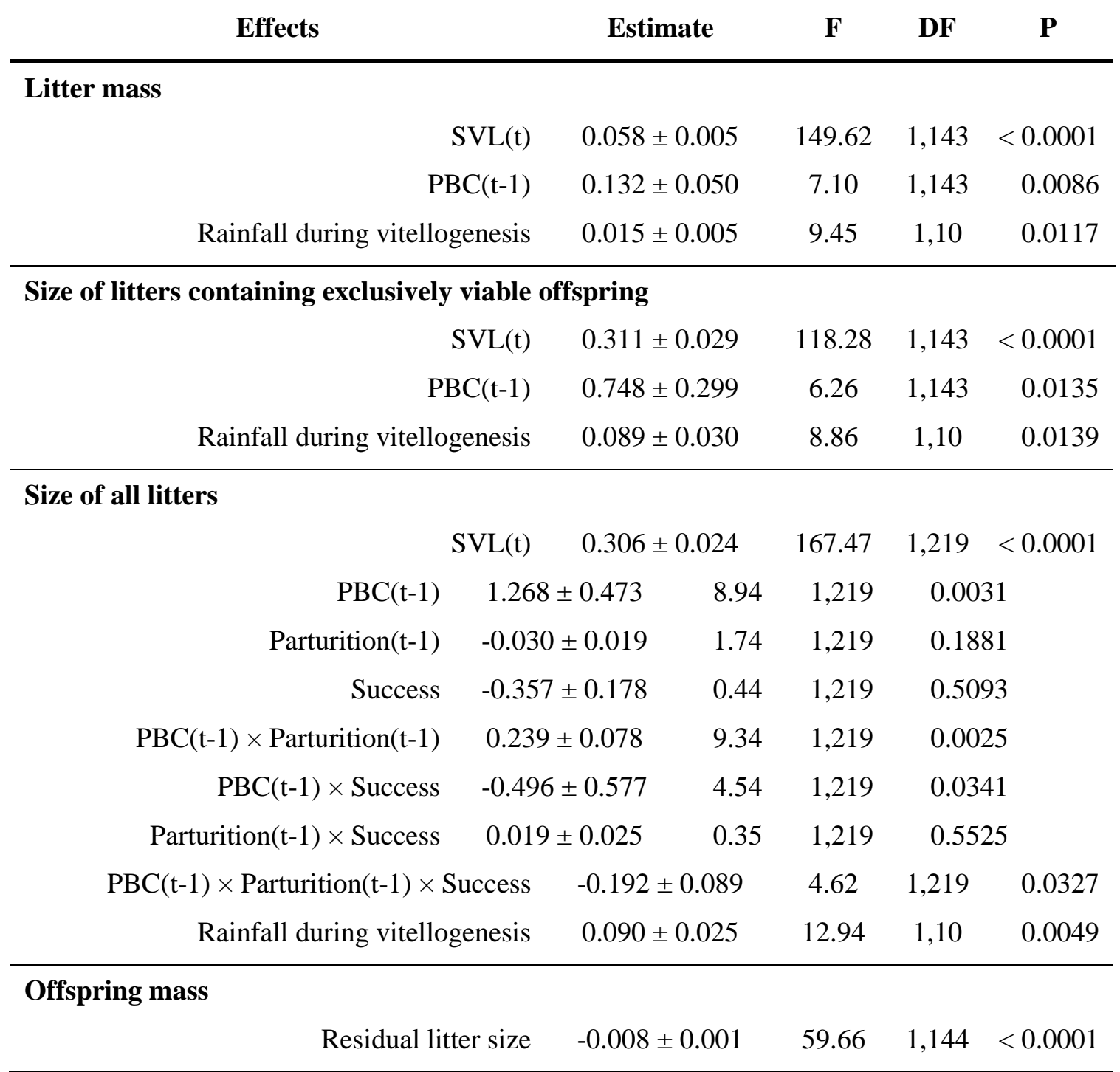


Table 2. Annual variations of reproductive traits. Estimates of year random effect for litter mass, size

569 of exclusively viable litters, offspring mass, and size of all litters. Estimates are given as standard

570 deviations (SD) calculated from a random model with no fixed effect ("annual variation" model), a mixed

571 effect model with significant intrinsic factors ("intrinsic factors" model) and a mixed effect model with

572 significant intrinsic and extrinsic factors ("final best model”, Table 1).

\begin{tabular}{rccccc} 
& $\boldsymbol{\sigma}_{\text {annual }}$ & $\boldsymbol{\sigma}_{\text {residual }}$ & ICC & LRT & P \\
\hline Litter mass & & & & & \\
Annual variation & $0.09[0.05 ; 0.19]$ & $0.29[0.25 ; 0.32]$ & 24.50 & 4.95 & 0.0260 \\
Intrinsic factors & $0.05[0.01 ; 0.15]$ & $0.21[0.18 ; 0.23]$ & 18.15 & 1.17 & 0.2786 \\
Final best model & $\sim 0$ & $0.21[0.18 ; 0.23]$ & 0 & & \\
\hline
\end{tabular}

\section{Size of litters containing exclusively viable offspring}

$\begin{array}{rccccc}\text { Annual variation } & 0.61[0.32 ; 1.16] & 1.59[1.42 ; 1.79] & 27.67 & 7.89 & 0.0050 \\ \text { Intrinsic factors } & 0.20[0.03 ; 1.38] & 1.25[1.11 ; 1.40] & 13.94 & 0.35 & 0.5542 \\ \text { Final best model } & \sim 0 & 1.23[1.10 ; 1.38] & 0 & & \end{array}$

\begin{tabular}{rccccc}
\hline Size of all litters & & & & & \\
Annual variation & $0.63[0.35 ; 1.13]$ & $1.68[1.53 ; 1.84]$ & 27.32 & 13.24 & 0.0003 \\
Intrinsic factors & $0.33[0.14 ; 0.76]$ & $1.26[1.15 ; 1.39]$ & 20.64 & 3.25 & 0.0716 \\
Final best model & $\sim 0^{\mathrm{a}}$ & $1.24[1.16 ; 1.39]$ & 0 & & \\
\hline
\end{tabular}

\section{Offspring mass ${ }^{\mathrm{b}}$}

\begin{tabular}{ccccccc} 
Annual variation & $0.0035[0.0010 ; 0.0125]$ & $0.0187[0.0167 ; 0.0210]$ & 15.93 & 1.03 & 0.3109 \\
Intrinsic factors & $0.0030[0.0009 ; 0.0103]$ & $0.0160[0.0142 ; 0.0179]$ & 15.90 & 1.08 & 0.2994 \\
\hline
\end{tabular}

573 Values between square brackets indicate the confidence interval.

$574 \sigma_{\text {annual }}=$ year effect standard deviation, $\sigma_{\text {residual }}=$ residual standard deviation, ICC $=$ intraclass correlation

575 coefficient (\% of total standard deviation), LRT = likelihood ratio test.

$576 \quad{ }^{\mathrm{a}} \sim 0$ indicates an estimate at the boundary of the parameter space.

$577 \quad{ }^{\mathrm{b}}$ Effects of extrinsic factors were not significant for offspring mass 
579 Table 3. Annual variation in the offspring mass and litter size trade-off. The trade-off was

580 investigated in litters containing exclusively viable offspring $(\mathrm{n}=157)$. Pearson's $\mathrm{r}$ correlation coefficient

581 was calculated between offspring mass and residual litter size for each year (see ESM 5 for results on

582 log-transformed values). Following on Christians (2000), we calculated the variance ratio as the ratio of

583 the variance in allocation [i.e. $\operatorname{var}\{\log ($ offspring mass $) / \log ($ litter mass $)\}]$ to the variance in investment

$584 \quad$ [i.e. $\operatorname{var}\{\log ($ litter mass $)\}]$.

585

\begin{tabular}{cccccc} 
Year & $\mathbf{n}$ & Pearson's $\mathbf{r}$ & $\mathbf{9 5 \%}$ confidence interval & $\mathbf{P}$ & $\begin{array}{c}\text { Variance } \\
\text { ratio }\end{array}$ \\
\hline 1991 & 11 & -0.415 & -0.813 to 0.246 & 0.204 & 0.0190 \\
1992 & 10 & -0.313 & -0.787 to 0.394 & 0.379 & 0.0152 \\
$\mathbf{1 9 9 3}$ & $\mathbf{2 1}$ & $\mathbf{- 0 . 4 9 3 *}$ & $\mathbf{- 0 . 7 6 2}$ to $-\mathbf{0 . 0 7 8}$ & $\mathbf{0 . 0 2 3} *$ & $\mathbf{0 . 0 1 8 9 *}$ \\
1994 & 18 & -0.226 & -0.627 to 0.269 & 0.366 & 0.0133 \\
$\mathbf{1 9 9 5}$ & $\mathbf{1 3}$ & $\mathbf{- 0 . 7 1 3 *}$ & $\mathbf{- 0 . 9 0 8}$ to $-\mathbf{0 . 2 6 7}$ & $\mathbf{0 . 0 0 6} *$ & $\mathbf{0 . 0 2 4 6} *$ \\
$\mathbf{1 9 9 6}$ & $\mathbf{1 5}$ & $\mathbf{- 0 . 6 1 1 ^ { * }}$ & $\mathbf{- 0 . 8 5 5}$ to $-\mathbf{0 . 1 4 3}$ & $\mathbf{0 . 0 1 6 *}$ & $\mathbf{0 . 0 1 9 5 *}$ \\
$\mathbf{1 9 9 7}$ & $\mathbf{1 2}$ & $\mathbf{- 0 . 8 7 0 *}$ & $\mathbf{- 0 . 9 6 3}$ to $-\mathbf{0 . 5 9 2}$ & $<\mathbf{0 . 0 0 1 *}$ & $\mathbf{0 . 0 4 5 1 ^ { * }}$ \\
1998 & 11 & -0.475 & -0.837 to 0.174 & 0.140 & 0.0169 \\
$\mathbf{1 9 9 9}$ & $\mathbf{1 1}$ & $\mathbf{- 0 . 7 0 5 *}$ & $\mathbf{- 0 . 9 1 7}$ to $-\mathbf{0 . 1 8 2}$ & $\mathbf{0 . 0 1 5 *}$ & $\mathbf{0 . 0 2 4 6 *}$ \\
2000 & 12 & -0.319 & -0.755 to 0.312 & 0.312 & 0.0163 \\
2001 & 10 & -0.305 & -0.784 to 0.402 & 0.392 & 0.0138 \\
2002 & 13 & -0.451 & -0.802 to 0.133 & 0.122 & 0.0148 \\
\hline
\end{tabular}




\section{FIGURE LEGENDS}

Figure 1. Reproductive cycle of the common lizard at Mont Lozère. During the course of our study, lizards were captured during mid-gestation in June and maintained in the laboratory until parturition (hollow lines). We calculated average weather conditions (1) during energy storage: from parturition (date 1: 8 August) to the start of hibernation (date 2: 30 September), (2) during vitellogenesis: from 1 May (date 3) to 21 May (date 4), and (3) during gestation before capture and maintenance in the laboratory: from 1 June (date 5) to capture (date 6: 21 June).

Figure 2. Variation in litter mass. Residual litter mass (residuals of litter mass from a linear regression against maternal SVL and previous postpartum body condition (PBC), see Table 1) is shown as means ( \pm SE) per year. Size of filled circles is proportional to sample size (range $=10-21)$. Solid line represents model predictions from Table 1. The slope estimate was robust to the exclusion of the year with the highest rainfall (slope $=0.016 \pm 0.007, \mathrm{~F}_{1,9}=2.18, \mathrm{P}=0.057$ ).

Figure 3. Variation in litter size. a) Postpartum body condition $(\mathrm{PBC})$ of the previous year was correlated with the size of litters containing exclusively viable offspring $(n=157)$. The solid line indicates model predictions (Table 1). b) PBC of the previous year was correlated with the size of litters containing nonviable offspring for late breeding females, but not for early breeding females. Model predictions are represented using a dashed line for early breeding females (parturition date $<$ mean parturition date) and a solid line for late breeders (parturition date > mean parturition date). Slopes estimates obtained from the model in Table 1 were positive and significant for late breeders $(n=42$, slope $=2.225 \pm 0.648, P=$ $0.0007)$ but not significantly different from zero in early breeders $(n=40$, slope $=0.063 \pm 0.690, P=$ 0.93). Data for litter sizes are residuals of a linear regression between litter size and maternal SVL.

Figure 4. Variation in the offspring mass and number trade-off. There is a negative correlation between the Pearson's correlation coefficient (r), calculated between offspring mass and residual litter size, and the variance ratio, calculated as the ratio of the variance in allocation to the variance in investment (see Table 3). Note that this negative correlation is still significant if we exclude the highest variance ratio (Pearson's $\mathrm{r}=-0.918$, range $=[-0.979 ;-0.707], \mathrm{P}<0.0001)$. 


\section{FIGURES}

Figure 1

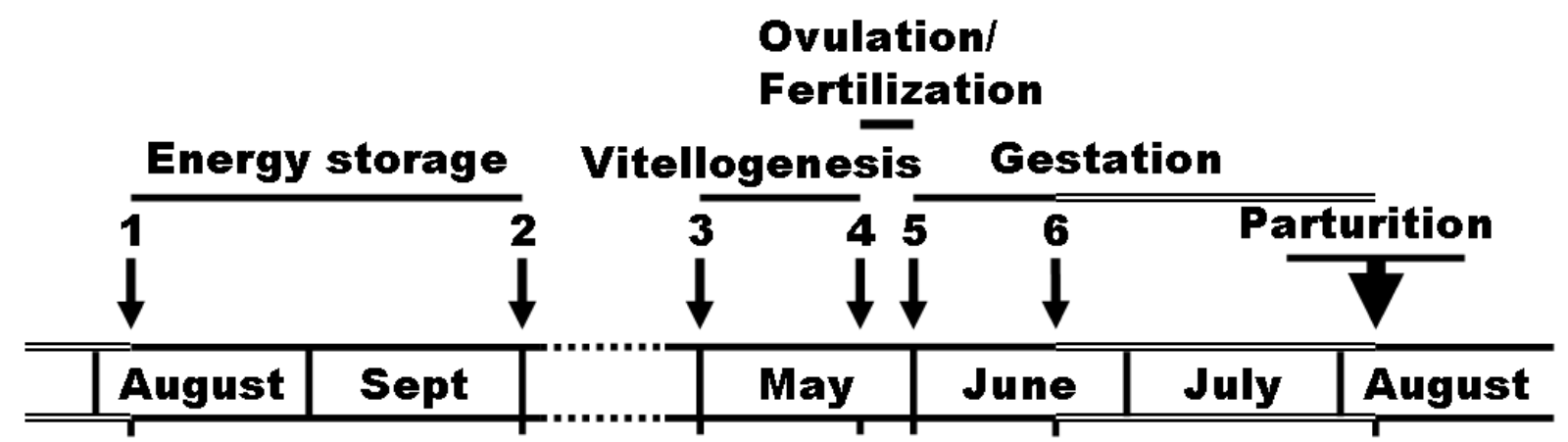

Figure 2

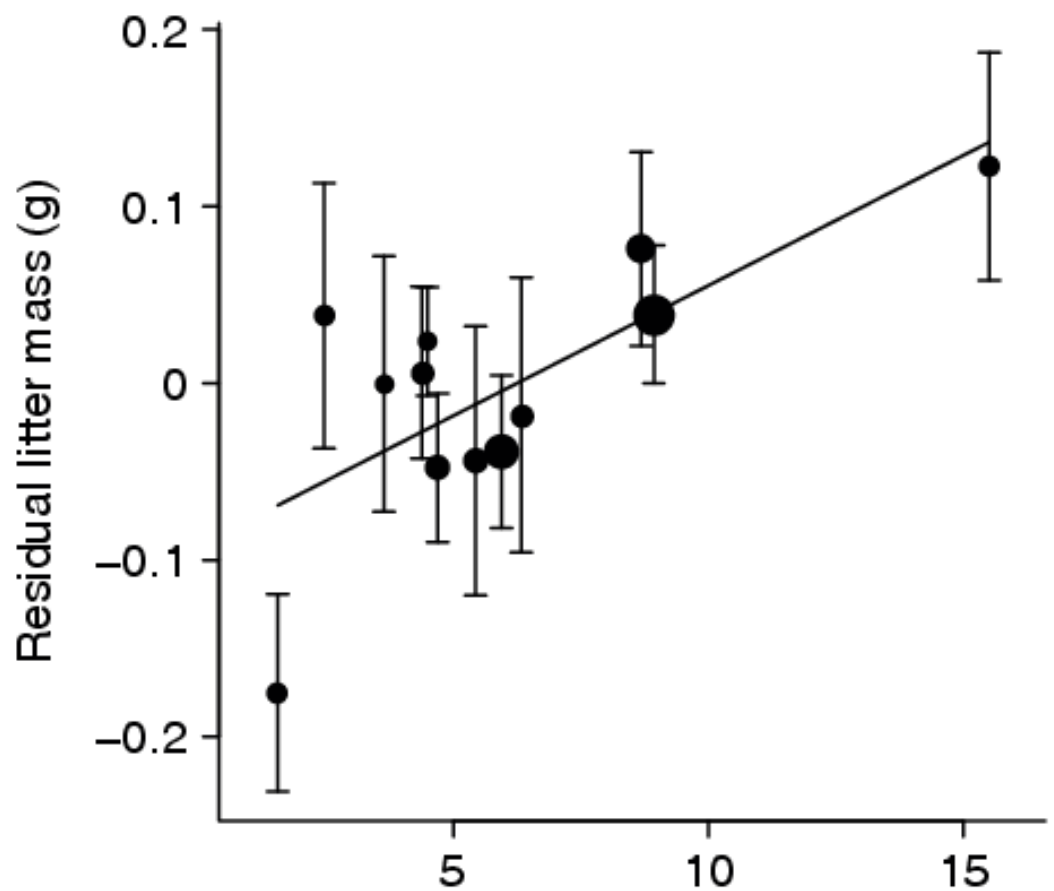

Rainfall during vitellogenesis ( $\mathrm{mm}$ )

Figure 3 

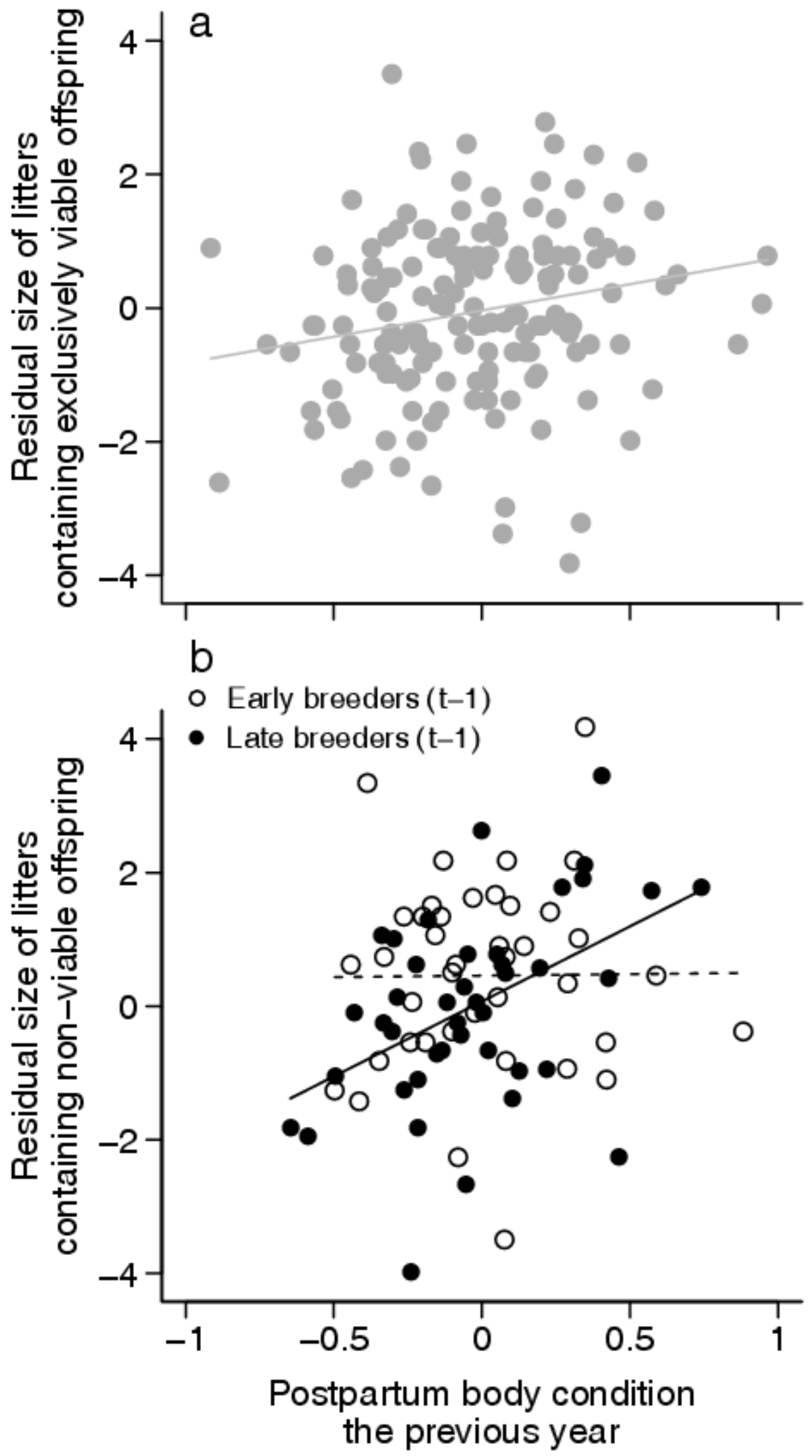

Figure 4 


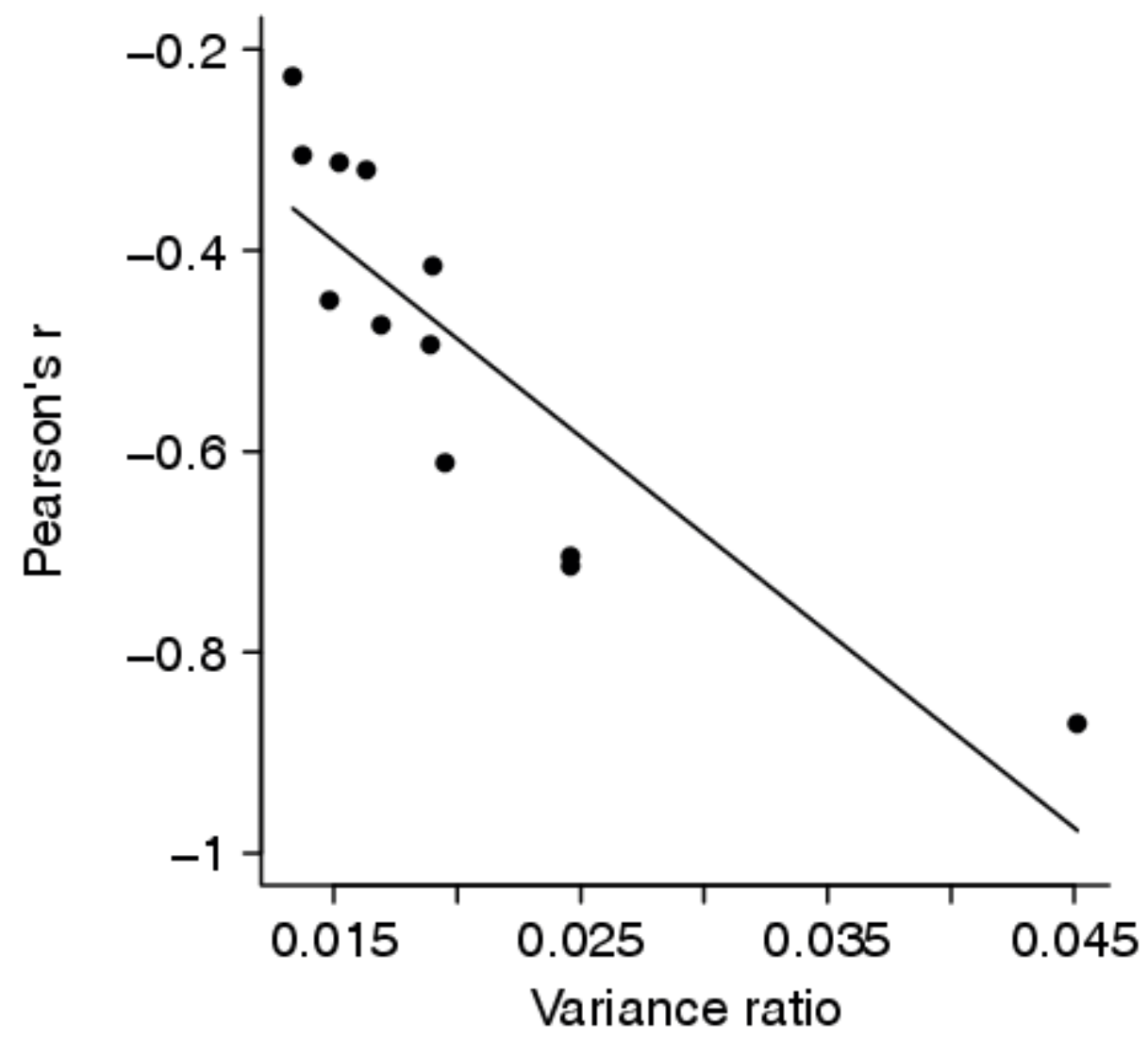

